\title{
A DESCRIPTIVE STUDY OF DIAGNOSTIC AND MANAGEMENT PROTOCOLS IN CHRONIC RHINOSINUSITIS
}

\author{
Budha Raju Varaprasada Varma1, Gonuru Vinod Kumar²
}

${ }^{1}$ Senior Resident, Department of ENT, Apollo Institute of Medical Sciences and Research. ${ }^{2}$ Associate Professor, Department of ENT, Apollo Institute of Medical Sciences and Research.

\begin{abstract}
BACKGROUND

Rhinosinusitis is an inflammatory process involving the mucous membrane of the nose and one or more sinuses. The last decade has seen the development of a number of guidelines as well as publications on the epidemiology, diagnosis and treatment of rhinosinusitis and nasal polyposis in U.S.A. and Europe. In our country, proper population surveys are required to know the exact prevalence of chronic rhinosinusitis. However, even from the limited data available, it is very apparent that chronic rhinosinusitis is a significant health problem resulting in considerable medical costs and severe impact on the health related quality of life.

This descriptive study was conducted to- 1 . To study the efficacy of clinical examination, diagnostic nasal endoscopy and CT scan in diagnosing chronic rhinosinusitis with and without polyps; 2 . To study the surgical techniques and surgical findings of all the patients of chronic rhinosinusitis undergoing endoscopic sinus surgery; 3. Patient's satisfaction will be assessed by comparing preoperative and post-operative Rhinosinusitis Disability Index.
\end{abstract}

\section{MATERIALS AND METHODS}

Our study was a descriptive study conducted at our hospital for a time period of 1 year. The study consisted of 52 cases having clinically diagnosed as chronic rhinosinusitis according to symptoms defined by rhinosinusitis task force.

\section{RESULTS}

There is a definitive male preponderance in our study with most of the patients coming from age groups between 20 - 60 years. This is comparable to most of the studies. Chronic rhinosinusitis with polyps (42.4\%), chronic rhinosinusitis without polyps (57.6\%), ENT examination could identify $34.6 \%$ of patients with polyps, which includes three categories. Sinonasal polyposis (27.7\%), Antrochoanal polyps (55.5\%), Allergic fungal polyposis (15.6\%). Postoperatively, patient's satisfaction is better in chronic rhinosinusitis without polyps.

\section{CONCLUSION}

Patient's satisfaction was assessed by comparing pre- and post-operative Rhinosinusitis Disability Index. Highly significant difference was noted when pre- and post-operative Rhinosinusitis Disability Index $(p=0.003)$ were compared. For patients with polyps, $\mathrm{P}$ value $=0.00$ and patients without polyps, $\mathrm{P}$ value $=0.00$.

\section{KEYWORDS}

Chronic Rhinosinusitis, Endoscopic Sinus Surgery, FESS, Allergic Rhinosinusitis.

HOW TO CITE THIS ARTICLE: Varma BRV, Kumar GV. A descriptive study of diagnostic and management protocols in chronic rhinosinusitis. J. Evolution Med. Dent. Sci. 2017;6(61):4463-4469, DOI: 10.14260/Jemds/2017/965

\section{BACKGROUND}

Chronic rhinosinusitis is quite a common disease of the nose and sinuses seen globally and in India. The incidence of rhinosinusitis is increasing in our country due to increasing air pollution, industrial fumes and allergic factors especially in the urban areas. In the rural areas also, rhinosinusitis is quite prevalent due to lack of proper hygiene and malnutrition resulting in low immunity.

The last decade has seen the development of a number of guidelines, consensus documents as well as publications on the epidemiology, diagnosis and treatment of rhinosinusitis and nasal polyposis in U.S.A. and Europe.

Financial or Other, Competing Interest: None.

Submission 08-07-2017, Peer Review 22-07-2017,

Acceptance 24-07-2017, Published 31-07-2017.

Corresponding Author:

Gonuru Vinod Kumar,

Plot No. 136,

Sardar Patel Colony,

Trimulgherry, Secunderabad,

Telangana, India.

E-mail: drvinnu2004@yahoo.co.in

DOI: $10.14260 /$ jemds $/ 2017 / 965$
In our country, proper population surveys are required to know the exact prevalence of chronic rhinosinusitis. However, even from the limited data available it is very apparent that chronic rhinosinusitis is a significant health problem resulting in considerable medical costs and severe impact on the health-related quality of life.

Rhinosinusitis is an inflammatory process involving the mucous membrane of the nose and one or more sinuses. The mucous membrane of the nose and sinuses is continuous and bears the brunt of any offending causative factor, especially bacterial infection. Chronic rhinosinusitis generally develops as a complication of viral or allergic inflammation of the upper respiratory tract. ${ }^{1}$ Although bacteria can be found in the sinuses of most patients who have CRS, the exact aetiology of the inflammation associated with this condition is uncertain.2,3 Chronic rhinosinusitis is a multifactorial disease. Factors contributing to rhinosinusitis can be mucociliary impairment, bacterial infection, allergy, swelling of the mucosa due to any reason and physical obstructions caused by anatomical variations in the nasal cavity or paranasal sinuses. Bachert and Colleagues ${ }^{4}$ suggested that bacterial superantigens may have a possible role in the pathophysiology of nasal polyposis. ${ }^{4}$ Most of the cases show 
presence of eosinophilic infiltration only. ${ }^{5}$ The origin of pathology in osteomeatal complex also plays a significant role in the pathogenesis of rhinosinusitis.

Nasal polyps and chronic rhinosinusitis are often considered as one disease entity, because it seems difficult to clearly differentiate between the two. Nasal polyposis is the ultimate manifestation of chronic inflammation. ${ }^{6}$

The lamina propria of the polyps is abundant with eosinophils and lymphocytes. Through the inflammation within these tissues is mediated by a number of cells namely fibroblasts, epithelial cells and endothelial cells. ${ }^{7}$ The causal relationship of allergic rhinitis to rhinosinusitis is conflicting. There is no question that there is a definite association of allergic rhinitis and CRS.8,9 Suzuki et al ${ }^{10}$ also showed an increase in activated eosinophils and neutrophils as well as Interleukin (IL)-5 in sinus effusions of allergic patients compared with non-allergic patients.

It is not confirmed whether the inflammation is infectious. It should be possible to diagnose a case of rhinosinusitis on the basis of detailed history and significant signs found during ENT examination. The analysis of signs and symptoms such as purulent discharge, nasal congestion, cough and any impairment of sense of smell together with the variation of intensity is important in diagnosing disease and monitoring treatment. However, in chronic cases with longstanding symptoms and no obvious signs, investigations in addition to a general ENT examination are necessary.

CT scan is invaluable for evaluation of the sinus disease, for assessment and road map during surgery. CT scan of PNS in coronal and axial views reveal mucosal changes deeper in osteomeatal complex and helps to correlate anatomical and pathological information. It also gives maximum information about the extent of disease assessing the contents in the sinus cavity and soft tissue lesions.

Routine ENT examination also includes endoscopic inspection of the nose. With Nasal Endoscopy, purulent secretions coming from sinus ostia, surgically treated sinus cavities and small polyps can be diagnosed at an early stage. Nasal Endoscopy combined with CT scan helps to locate the site and delineate the extent of nasal and sinus diseases. With the introduction of improved computer software, the imaging techniques have become both fascinating and rewarding.

Patients who are allergic must be carefully evaluated, as even minor allergies may cause enough of an exacerbation of chronic rhinosinusitis to cause dramatic worsening of symptoms. In addition to environmental controls, the antiallergic therapy is also used to manage these patients. Any patient with chronic rhinosinusitis poorly responsive to medical treatment should have an extensive immunological evaluation including immunoglobulin levels. Children should be evaluated for cystic fibrosis.

In the past chronic sinusitis cases used to be dealt by repeated antral punctures and washes resulting in transitory improvement of symptoms. During that time, the concept or myth of the patients suffering from chronic rhinosinusitis used to be that sinusitis is a life-long untreatable disease. This view is now fast changing with the replacement of conventional external surgical techniques like Lynch Howarth and Caldwell Luc operations by less invasive and more effective techniques such as Endoscopic sinus surgery.

From the management point of view, patients with chronic rhinosinusitis in their early stages should first be treated with antibiotics and anti-allergic drugs. In case the chronic rhinosinusitis is associated with nasal polyps, an appropriate course of oral steroids in tapering doses may help the patients. In case signs and symptoms persist or recur after medical treatment endoscopic sinus surgery should be considered, which has been found quite effective for the treatment of chronic rhinosinusitis.

Various new techniques of endoscopic sinus surgery have emerged including lasers to provide optimal results. Septum correction and endoscopic turbinate reduction along with endoscopic sinus surgery are advocated whenever necessary. Patient who has recurrent disease must be evaluated for allergic fungal and invasive fungal disease.

Some patients who do not respond to surgery may need selective antibiotics and anti-allergic therapy for 6 - 8 weeks to clear up infection and to control allergic symptoms. The role of supportive measures like nasal irrigation or spray with saline solution is also equally important keeping the chronicity of the disease in view. Treatment strategy for each patient must therefore be carefully planned.

\section{Aims and Objectives}

1. To study the efficacy of clinical examination, diagnostic nasal endoscopy and CT scan in diagnosing chronic rhinosinusitis with and without polyps.

2. To study the surgical techniques and surgical findings of all the patients of chronic rhinosinusitis undergoing endoscopic sinus surgery.

3. Patient satisfaction will be assessed by comparing preoperative and post-operative Rhinosinusitis Disability Index.

\section{MATERIALS AND METHODS}

Our study was a descriptive study conducted at Dr. Pinnamaneni Siddhartha Institute of Medical Sciences and Research Foundation, Gannavaram, Krishna District for a time period of 1 year. The study consisted of 52 cases having clinically diagnosed as chronic rhinosinusitis according to symptoms defined by Rhinosinusitis task force.

\section{RESULTS}

The study includes 52 patients having clinically diagnosed as chronic rhinosinusitis according to definition proposed by International task force on rhinosinusitis. ${ }^{11}$

\section{Rhinosinusitis Symptoms/Signs (Requires Two Major or One Major and Two Minor Factors)}

\begin{tabular}{|c|c|c|c|}
\hline & Major Factors & & Minor Symptoms \\
\hline 1. & Facial pain/ Pressure & 1. & Headache \\
\hline 2. & Facial congestion/ Fullness & 2. & Fever (Non-Active) \\
\hline 3. & Nasal obstruction/ Blockage & 3. & Halitosis \\
\hline 4. & $\begin{array}{c}\text { Nasal discharge/ Purulent/ } \\
\text { Discoloured posterior drainage }\end{array}$ & 4. & Fatigue \\
\hline 5. & Hyposmia/ Anosmia & & \\
\hline 6. & $\begin{array}{c}\text { Purulence on nasal } \\
\text { examination }\end{array}$ & & \\
\hline 7. & Fever (Acute RS only) & \\
\hline Table 1. Criteria for Diagnosing Chronic Rhinosinusitis \\
\hline
\end{tabular}




\section{Geographical Distribution}

In our study, patients mainly came from Krishna (76.9\%) and West Godavari (19.2\%) districts of Andhra Pradesh and few were from other places.

\section{Age Distribution}

Patients mainly presented in the age groups between $21-40$ years $(61.5 \%)$ and $41-60$ years $(25.1 \%)$. However, there are 5 patients below the age of $20(9.6 \%)$.

\begin{tabular}{|c|c|c|c|c|c|}
\hline \multirow{2}{*}{ Age } & \multirow{2}{*}{ Numbers } & \multicolumn{2}{|c|}{ CRS without Polyps } & \multicolumn{2}{|c|}{ CRS with Polyps } \\
\hline & & No. & $\%$ & No. & $\%$ \\
\hline $0-20$ & 5 & 2 & $40 \%$ & 3 & $60 \%$ \\
\hline $21-40$ & 32 & 22 & $68.7 \%$ & 10 & $31.2 \%$ \\
\hline $41-60$ & 13 & 6 & $46.1 \%$ & 7 & $53.8 \%$ \\
\hline $61-80$ & 2 & 0 & $0 \%$ & 2 & $100 \%$ \\
\hline
\end{tabular}

\section{Gender Distribution}

Out of 52 patients suffering from chronic rhinosinusitis, $61.5 \%$ were males and $38.5 \%$ were females showing male preponderance.

\section{Sex Distribution in Relation to Presence or Absence of Polyps}

Out of 32 male patients $43.7 \%$ has polyps and $56.3 \%$ has no polyps and out of 20 female patients $60 \%$ has no polyps and $40 \%$ have polyps.

\section{Socio-Economic Status}

Socio-economic status is poor in $53.8 \%$ of patients and middle class in $46.2 \%$ of patients. No patients from upper socio-economic class.

\section{Distribution Based on Symptoms}

All the 52 patients were evaluated for following symptoms. Nasal obstruction is the most common symptom seen in 96.1\% patients, swelling of cheek is present in one case in which chronic rhinosinusitis is associated with osteomyelitis of left maxilla.

\begin{tabular}{|c|c|c|}
\hline Symptoms & Number & $\%$ \\
\hline Nasal obstruction & 50 & $96.1 \%$ \\
\hline Nasal discharge & 37 & $71.1 \%$ \\
\hline Postnasal drip & 20 & $38.4 \%$ \\
\hline Sneezing & 13 & $25 \%$ \\
\hline Headache and Facial pain & 35 & $67.3 \%$ \\
\hline Epistaxis & 3 & $5.7 \%$ \\
\hline Disturbance of smell & 17 & $32.6 \%$ \\
\hline Swelling or deformity & 1 & $1.9 \%$ \\
\hline Snoring & 8 & $15.3 \%$ \\
\hline Change in speech & 8 & $15.3 \%$ \\
\hline
\end{tabular}

\section{Clinical Examination}

Clinical examination was done by anterior rhinoscopy and Diagnostic Nasal Endoscopy in all patients.

\section{ENT Examination}

Septal deviation is the most common sign present in $67.3 \%$ of patients. Polyposis which includes sinonasal polyposis, antrochoanal polyps and polyps with fungal aetiology is present in $34.6 \%$ of cases.

\begin{tabular}{|c|c|c|c|}
\hline \multicolumn{2}{|c|}{ Sign } & Number & \% \\
\hline \multicolumn{2}{|c|}{ Septal deviation } & 35 & $67.3 \%$ \\
\hline \multicolumn{2}{|c|}{ Pale mucosa } & 11 & $21.1 \%$ \\
\hline Turbinate & Inferior & 18 & $34.6 \%$ \\
\hline Hypertrophy & Middle & 14 & $26.9 \%$ \\
\hline \multicolumn{2}{|c|}{ Discharge } & 21 & $40.3 \%$ \\
\hline \multicolumn{2}{|c|}{ Polyp } & 18 & $34.6 \%$ \\
\hline 1. Sinonasal polyposis & 5 & $27.7 \%$ \\
\hline 2. Antrochoanal polyp & 10 & $55.5 \%$ \\
\hline 3. Allergic fungal polyposis & 3 & $16.6 \%$ \\
\hline
\end{tabular}

Table 4. Distribution of Clinical Examination Findings

\section{Diagnostic Nasal Endoscopy}

Diagnostic Nasal Endoscopy was done in all 52 patients. Septal deviation is the most common sign present in $71.1 \%$ of cases and purulent nasal discharge is second most common sign present in $40.3 \%$ of cases. Nasal polyposis which includes Sinonasal polyposis (23.8\%), Antrochoanal polyps $(47.6 \%)$ and Allergic fungal sinusitis $(28.5 \%)$ is present. Polyps are better identified in Diagnostic Nasal Endoscopy (21) than in anterior rhinoscopy (18).

\begin{tabular}{|c|c|c|c|}
\hline \multicolumn{2}{|c|}{ Sign } & Number & \% \\
\hline \multicolumn{2}{|c|}{ Septal deviation } & 37 & $71 \%$ \\
\hline \multicolumn{2}{|c|}{ Pale mucosa } & 11 & $21.1 \%$ \\
\hline Turbinate & Inferior & 18 & $34.6 \%$ \\
\hline Hypertrophy & Middle & 14 & $26.9 \%$ \\
\hline \multicolumn{2}{|c|}{ Discharge (Purulent) } & 21 & $40.3 \%$ \\
\hline \multicolumn{2}{|c|}{ Polyps } & 21 & $40.3 \%$ \\
\hline \multicolumn{2}{|c|}{ 1. Sinonasal polyposis } & 5 & $23.8 \%$ \\
\hline \multicolumn{2}{|c|}{ 2. Antrochoanal polyp } & 10 & $47.6 \%$ \\
\hline \multicolumn{2}{|c|}{ 3. Allergic fungal polyposis } & 6 & $28.5 \%$ \\
\hline
\end{tabular}

Table 5. Distribution of Diagnostic Nasal Endoscopy Findings

\section{Radiological Examination}

Both anatomical variations and pathological findings were studied in CT scan coronal cuts.

\section{Anatomical Variations}

Pneumatised middle turbinate is the most common variation detected in $34.6 \%$ cases. Agger nasi is the second most common anatomical variant. 


\begin{tabular}{|c|c|c|}
\hline Anatomical Variations & No. of Cases & $\%$ \\
\hline Agger nasi & 9 & $17.3 \%$ \\
\hline Pneumatisation of MT & 18 & $34.6 \%$ \\
\hline Enlarged ethmoidal bulla & 7 & $13.4 \%$ \\
\hline Paradoxical MT & 6 & $11.5 \%$ \\
\hline Everted uncinate & 1 & $1.9 \%$ \\
\hline Haller cell & 4 & $7.6 \%$ \\
\hline Onodi cell & 6 & $11.5 \%$ \\
\hline Frontal sinus cells & 6 & $11.5 \%$ \\
\hline
\end{tabular}

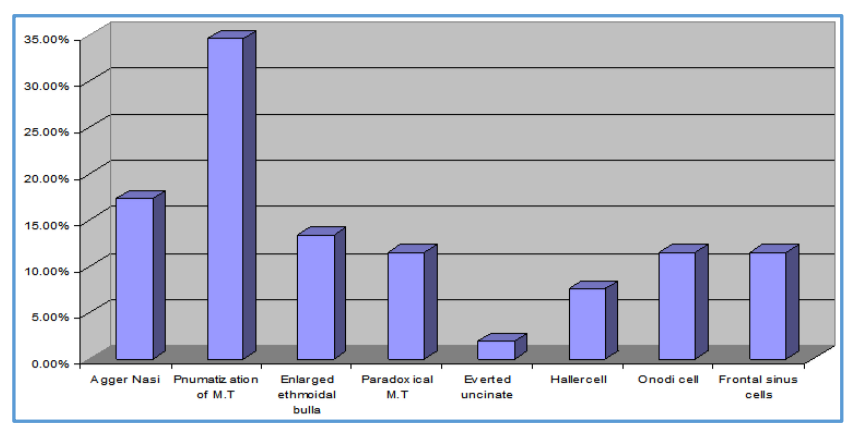

Figure 1. Anatomical Variations in CT-PNS

\section{Pathological Findings}

OMC block with maxillary sinusitis is present in $96.1 \%$ of cases. Total number of polyposis identified in CT scan are 22 cases which includes $45.4 \%$ of antrochoanal polyp, $31.8 \%$ of allergic fungal polyposis, $22.7 \%$ of Sinonasal polyposis. CT scan is a better diagnostic tool to identify polyps (Allergic fungal sinusitis) than Anterior rhinoscopy and Diagnostic Nasal Endoscopy.

\begin{tabular}{|c|c|c|}
\hline Pathological Variations & No. of Cases & $\mathbf{\%}$ \\
\hline Septal deviation & 35 & $67.3 \%$ \\
\hline Osteomeatal complex block & 50 & $96.1 \%$ \\
\hline Maxillary sinusitis & 50 & $96.1 \%$ \\
\hline Anterior ethmoidal sinusitis & 45 & $86.5 \%$ \\
\hline Posterior ethmoidal sinusitis & 35 & $67.3 \%$ \\
\hline Sphenoid sinusitis & 18 & $34.6 \%$ \\
\hline Frontal sinusitis & 22 & $42.3 \%$ \\
\hline Polyposis & 22 & $42.3 \%$ \\
\hline 1. Sinonasal polyposis & 5 & $22.7 \%$ \\
\hline 2. Antrochoanal polyp & 10 & $45.4 \%$ \\
\hline $3 . \quad$ Allergic fungal & 7 & $31.8 \%$ \\
\hline
\end{tabular}

Table 7. Distribution of Pathological Variations in CT Scan

Chronic Rhinosinusitis with Polyps and Chronic Rhinosinusitis without Polyps

Pathologically chronic rhinosinusitis is divided into two major groups depending upon presence or absence of polyps. In our study, there were polyps in $42.4 \%$ of cases and there were no polyps in $57.6 \%$ of cases.

\begin{tabular}{|c|c|c|}
\hline Cases & Number & $\mathbf{\%}$ \\
\hline Chronic rhinosinusitis with & 22 & $42.4 \%$ \\
\hline Chronic rhinosinusitis & 30 & $57.6 \%$ \\
\hline Table 8.2 Distribution of Polyps in Chronic Rhinosinusitis
\end{tabular}

\section{Haematological Investigations}

Routine blood investigations were done in all the cases and absolute eosinophil count was raised in 7 (3.4\%) cases, which were having history of allergy.

\section{Surgical Management}

All the 52 patients having chronic rhinosinusitis underwent functional endoscopic sinus surgery. Uncinectomy and middle meatal antrostomy was performed in all cases. Surgical findings which involve mucosal oedema (21.1\%), polyps (42.3\%), discharge (34.6\%) and fungal debris (13.4\%).

\begin{tabular}{|c|c|c|}
\hline Technique & No. of Cases & $\%$ \\
\hline Septoplasty & 35 & $67.3 \%$ \\
\hline Uncinectomy & 52 & $100 \%$ \\
\hline Middle meatal antrostomy & 52 & $100 \%$ \\
\hline Anterior ethmoidectomy & 45 & $86.5 \%$ \\
\hline Posterior ethmoidectomy & 35 & $67.3 \%$ \\
\hline Sphenoidotomy & 18 & $34.6 \%$ \\
\hline Frontal recess surgery & 22 & $42.3 \%$ \\
\hline Reduction of MT & 18 & $34.6 \%$ \\
\hline Partial inferior turbinectomy & 14 & $26.9 \%$ \\
\hline Polypectomy & 22 & $42.3 \%$ \\
\hline \multicolumn{3}{|c|}{$\begin{array}{c}\text { Table 9. Distribution of Techniques in Endoscopic Sinu } \\
\text { Surgery }\end{array}$} \\
\hline
\end{tabular}

\begin{tabular}{|c|c|c|}
\hline Surgical Findings & No. of Cases & \% \\
\hline Mucosal oedema & 11 & $21.1 \%$ \\
\hline Polyps & 22 & $42.3 \%$ \\
\hline Discharge & 18 & $34.6 \%$ \\
\hline Fungal debris & 7 & $13.4 \%$ \\
\hline Table 10. Distribution of Surgical Findings in Endoscopic \\
Sinus Surgery \\
\hline
\end{tabular}

\section{Post-0p Diagnostic Nasal Endoscopy}

Endoscopy showed presence of synechiae in $15.3 \%$ cases, persistence of discharge in $9.6 \%$ cases.

\section{Rhinosinusitis Disability Index}

Patient's satisfaction before and after surgery were noted for patients having chronic rhinosinusitis with and without polyps separately. Postoperatively, patient's satisfaction is better in chronic rhinosinusitis without polyps.

\section{DISCUSSION}

Chronic rhinosinusitis is a common disease affecting several people all over the world. Lot of research work has gone on several aspects of chronic rhinosinusitis. As the disease affects functions of nose and paranasal sinuses as well as quality of life, a number of guidelines and consensus have been published. American Academy of Otolaryngology and Head and Neck Surgery (AAOHNS) ${ }^{12}$ has formed a task force to develop clarification and protocols for management of chronic rhinosinusitis.

\section{Epidemiology of Chronic Rhinosinusitis}

According to National Ambulatory Medical Care Survey data (NAMCS) in the USA, ${ }^{13}$ Rhinosinusitis is the most common 
diagnosis for which an antibiotic is prescribed. Rhinosinusitis accounts for $9 \%$ and $21 \%$ of all paediatric and adult antibiotic prescriptions in 2002. High prevalence of chronic rhinosinusitis was confirmed by a survey suggesting that $16 \%$ of adult US population has chronic rhinosinusitis. A survey of 1200 households in Nottingham, $\mathrm{UK}^{14}$ revealed that $13.7 \%$ has CRS. Unfortunately, no epidemiological data could be found.

\section{Incidence}

The present study evaluated 52 patients of both the sexes who were surgically treated for chronic rhinosinusitis in Dr. PSIMS for a time period of one year. The study consisted of patients who attended both general outpatient clinic and also 'Aarogyasri' outpatient clinic. As endoscopic sinus surgery is included in 'Aarogyasri' (A social welfare program initiated by Government of Andhra Pradesh for the population below the poverty line), hence this does not include true incidence of chronic rhinosinusitis in general population.

\section{Diagnostic Criteria}

The patients were selected based on the symptoms defined by task force on rhinosinusitis.

Rhinosinusitis symptoms and signs (requires two major or one major and two minor factors).

\section{Geographical Distribution}

In our study, patients mainly came from Krishna (76.9\%) and West Godavari (19.2\%) districts of Andhra Pradesh, two cases were from other places. Geographically, our hospital lies between Krishna and West Godavari districts, so $96 \%$ of cases came from these districts. Rest of the two cases was referred from other places.

\section{Age Distribution}

Patients mainly presented in the age groups between $21-40$ years $(61.5 \%)$ and $41-60$ years $(25.1 \%)$. However, there were 5 patients below the age of 20 years (9.6\%); $86.7 \%$ of cases were in the age group between $(21-60)$.

\section{Sex Distribution}

Out of 52 patients suffering from chronic rhinosinusitis $61.5 \%$ were males and $38.5 \%$ were females, showing male preponderance. In a Canadian study, 15 prevalence of chronic rhinosinusitis was high in females than in male subjects. In our study, the prevalence was high in males than in females.

\section{Socioeconomic Status}

All the patients belonged to middle and low socioeconomic classes. As the hospital is affiliated to a medical college, there were no patients from the upper socioeconomic class.

\section{Distribution Based on Symptoms}

All the 52 patients were evaluated for the following symptoms- Nasal obstruction (96.1\%), Nasal discharge (71.1\%), Postnasal drip (38.4\%), Sneezing (25\%), Headache and Facial pain (67.3\%), Epistaxis (5.7\%), Disturbance of smell (32.6\%), Swelling or deformity (1.9\%), snoring (15.3\%) and Change in speech (15.3\%).

\section{Clinical Examination}

All the 52 patients in the study were evaluated by detailed ENT examination, Diagnostic Nasal Endoscopy and
Radiological evaluation. We have found two major groups of Chronic rhinosinusitis.

1. CRS with polyps (42.4\%).

2. CRS without polyps (57.6\%).

\section{ENT Examination}

Detailed ENT examination was done for all the patients and following signs were noted- Septal deviation (67.3\%), Pale mucosa $(21.1 \%)$, Inferior turbinate hypertrophy $(34.6 \%)$, Middle turbinate hypertrophy (26.9\%), Discharge (40.3\%), Polyps (34.6\%). Chronic rhinosinusitis without polyposis accounted for $65.4 \%$ of patients and with Polyposis which include Sinonasal polyposis (27.7\%), Antrochoanal polyps (55.5\%) and Allergic fungal polyposis (16.6\%) accounts for $34.6 \%$ of cases.

\section{Diagnostic Nasal Endoscopy}

Diagnostic Nasal Endoscopy was done for all the 52 patients. The signs noted are septal deviation (71.1\%), pale mucosa (21.1\%), Inferior Turbinate Hypertrophy (34.6\%), Middle Turbinate Hypertrophy (26.9\%) and Purulent discharge (40.3\%). Polyposis which include sinonasal polyposis (23.8\%), Antrochoanal polyps (47.6\%) and Allergic fungal polyposis $(28.5 \%)$ was present in $40.3 \%$ of patients.

Three patients having polyps were identified by Diagnostic Nasal Endoscopy that was not seen by ENT examination. This is because the polyps were small and confined to middle meatus. Hence, Diagnostic Nasal Endoscopy can pick up small polyps that were not identified by ENT examination, increasing the sensitivity of the investigation on Diagnostic Nasal Endoscopy (34.6\% $40.3 \%)$.

\section{CT Scan}

Both anatomical variations and pathological findings were studied in CT coronal cuts in all the 52 patients.

\section{Anatomical Variations}

The Anatomical variations identified in CT are Agger nasi (17.3\%), Pneumatisation of MT (34.6), Enlarged ethmoid bulla (13.4\%), Paradoxical MT (11.5\%), Everted Uncinate (1.9\%), Haller cell $(7.6 \%)$, Onodi cell $(11.5 \%)$ and Frontal sinus cells $(11.5 \%)$.

\section{Pathological Findings}

Pathological findings noted were Septal deviation (67.3\%), Osteomeatal complex block (96.1\%), Maxillary sinusitis (96.1\%), Anterior ethmoidal sinusitis (86.5\%), Posterior ethmoidal sinusitis (67.3\%), Sphenoid sinusitis (34.6\%), Frontal sinusitis (42.3\%), Polyps which included sinonasal polyposis (22.7\%), Antrochoanal polyps (45.4\%) and Allergic Fungal Polyposis (31.8\%) are present in $42.3 \%$ of patients. The CT scan identified one more patient having nasal polyposis that was not identified by Diagnostic Nasal Endoscopy and ENT examination (from 34.6\% which was identified on ENT examination, $40.3 \%$ in Diagnostic Nasal Endoscopy to $42.4 \%$ that was diagnosed on CT scan). It proves to state that CT scan, Diagnostic Nasal Endoscopy and ENT examination were complimentary to each other for diagnosing nasal polyposis. CT scan has also been used for 
staging of the disease by the Lund-Mackay system proposed by the task force on rhinosinusitis of the AAO-HNS.11

In a study conducted by Dua and Chopra ${ }^{16}$ regarding CT scan paranasal sinuses findings in CRS, they found that in majority of patients osteomeatal complex and anterior ethmoids were involved in $88 \%$ patients, agger nasi cells in $40 \%$, concha bullosa and Haller cells in $16 \%$ of patients. Apart from these, deviated nasal septum was found in $40 \%$ of the patients. In our study, the most common anatomical variant was Pneumatisation of middle turbinate (34.6\%), Agger nasi (17.3\%), Paradoxical middle turbinate $(11.5 \%)$, the most common pathological findings were Osteomeatal complex block (96.1\%) and anterior ethmoidal sinusitis (86.5\%).

\section{Haematological Examination}

Haematological examination was done in all 52 patients. Absolute eosinophil count was increased in $3.4 \%$ of all cases having history of allergy.

\section{Surgical Management}

All the 52 patients having chronic rhinosinusitis underwent functional endoscopic sinus surgery, out of which four of the patients were for revision surgery. Surgery was planned after appropriate medical treatment. Surgery was done by the following techniques: Uncinectomy (100\%), Middle meatal antrostomy (100\%), Anterior ethmoidectomy (86.5\%), Posterior ethmoidectomy (67.3\%), Sphenoidotomy (34.6\%) Frontal recess surgery $(42.3 \%)$ and Reduction of middle turbinate (34.6\%). Auxiliary surgeries such as septoplasty and partial inferior turbinectomy $(26.9 \%)$ were done to gain access to middle meatus and for relieving nasal obstruction.

1. Uncinectomy and middle meatal antrostomy was done in all 52 patients $(100 \%)$.

2. Uncinectomy and middle meatal antrostomy alone was done in 7 cases (13.4\%).

3. Uncinectomy and middle meatal antrostomy and anterior ethmoidectomy was done in 45 (86.5\%) patients.

4. Uncinectomy and middle meatal antrostomy, anterior and posterior ethmoidectomy was done in 35 (67.3\%) patients.

5. Uncinectomy and middle meatal antrostomy, ethmoidectomy and frontal recess surgery was done in $22(42.3 \%)$ patients.

6. Uncinectomy and middle meatal antrostomy ethmoidectomy, frontal recess surgery and sphenoidotomy were done in $18(34.6 \%)$ patients.

Uncinectomy and middle meatal antrostomy was done for antrochoanal polyps and isolated maxillary sinusitis. We have not found isolated frontal and sphenoid sinusitis. For all the patients having sinonasal polyposis and allergic fungal sinusitis, endoscopic polypectomy was done which was followed by appropriate ethmoidectomy. In case of antrochoanal polyps, polypectomy was followed by partial ethmoidectomy.

Endoscopic sinus surgery was done to remove the pathology from osteomeatal complex area to facilitate ventilation of sinuses thereby decreasing nasal secretions, reduction of diseased sinus mucosa by removal of polypoid tissue, improving olfaction and providing relief from nasal obstruction. Keeping the objectives of endoscopic sinus surgery, all 52 patients underwent appropriate exenteration of ethmoid cells and thereby obtaining wider access to major sinuses.

In a study conducted by Deal and Kauntakis, ${ }^{17}$ regarding significance of nasal polyps in chronic rhinosinusitis symptoms and surgical outcome in 201 patients having chronic rhinosinusitis with and without polyps they found that symptoms score was high in patients with polyps and surgical outcome was equally good when compared to patients suffering from chronic rhinosinusitis without polyps. In our study, symptoms score was high in patients having polyps and surgical outcome was equally good in patients with and without polyps. No intraoperative or preoperative complications were encountered in any of the patients in our study, though minor and major complications have been described in literature. ${ }^{18}$

\section{Post-Operative Management}

Nasal pack was removed on second postoperative day. Patients were given medical treatment in the form of antibiotics, decongestants, analgesics and anti-histamines for two weeks. Decongestant and saline nasal drops were given in immediate post-operative period.

\section{Surgical Outcome}

1. Surgical outcome was assessed by postoperative Diagnostic Nasal Endoscopy.

2. Patient's satisfaction was measured by comparing preoperative and postoperative Rhinosinusitis Disability Index form.

\section{Post-Operative Diagnostic Nasal Endoscopy}

Diagnostic Nasal Endoscopy showed the presence of synechia in 8 patients and presence of discharge in 5 patients, rest of the patients were free of any pathological findings postoperatively. All $100 \%$ had well-healed ethmoid cavities.

\section{Rhinosinusitis Disability Index}

The patients were given Rhinosinusitis Disability Index form which contains questions regarding physical, functional and emotional factors which was filled during preoperative and postoperative periods.

Rhinosinusitis Disability Index is a recently designed validated measure that has not been used much in clinical studies. In a study conducted by Birch and Saleh in 53 patients with chronic rhinosinusitis, they found that $\mathrm{P}$ value= 0.02 when preoperative and postoperative RSDI scores were compared. In our study, we divided patients with chronic rhinosinusitis into patients with and without polyps. Patients with chronic rhinosinusitis with polyps had significant difference in outcome when compared to preoperative and postoperative RSDI scores $(\mathrm{P}=0.00)$. In patients with chronic rhinosinusitis without polyps, the RSDI index for preoperative and postoperative periods also showed significant difference $(\mathrm{p}$ value $=0.00)$.

\section{CONCLUSION}

The present study includes 52 patients having chronic rhinosinusitis as defined by chronic rhinosinusitis task force. All the patients underwent endoscopic sinus surgery in an 
institute in a time period of 1 year with a mean follow-up period of three months.

All the 52 patients were evaluated by detailed ENT examination, Diagnostic Nasal Endoscopy and CT scan. MRI (PNS) scan was not done in any patient in the series, because there is no periorbital and intracranial extension.

$96.2 \%$ of patients belonged to Krishna and West Godavari Districts of Andhra Pradesh as the hospital catered to the people of the two districts. True incidence of chronic rhinosinusitis could not be evaluated in this study because the patients belonged to two categories- one category of patients who were attending outpatient clinic and another category included patients who were advised surgery under Aarogyasri scheme.

There is a definitive male preponderance in our study with most of the patients coming from age groups between 20 - 60 years. This is comparable to most of the studies.

1. Clinico-pathologically, patients were divided into two major groups.

2. Chronic rhinosinusitis with polyps (42.4\%).

3. Chronic rhinosinusitis without polyps (57.6\%).

4. ENT examination could identify $34.6 \%$ of patients with polyps, which includes three categories.

5. Sinonasal polyposis $(27.7 \%)$.

6. Antrochoanal polyps (55.5\%).

7. Allergic fungal polyposis (15.6\%).

Diagnostic Nasal Endoscopy confirmed these findings and also could diagnose early polyposis in three more patients that was not identified by ENT examination. CT scan confirmed the presence of polyps and could identify one more case of polyposis, making the percentage of patients of chronic rhinosinusitis with polyposis $42.3 \%$. Hence, all three are complimentary to each other in diagnosing nasal polyposis.

All 52 patients underwent endoscopic sinus surgery, uncinectomy and middle meatal antrostomy were done in all the cases. Polypectomy was done in $42.3 \%$ of cases; anterior and posterior ethmoidectomy was done in $67.3 \%$ patients; ethmoidectomy and frontal recess surgery were done in $42.3 \%$ patients; ethmoidectomy, frontal recess surgery and sphenoidotomy was done in $34.6 \%$ patients. There were no preoperative and postoperative complications in any of the patients.

Surgical outcome was assessed by postoperative Diagnostic Nasal Endoscopy, which showed synechiae and presence of persistent discharge in a few cases. Patient's satisfaction was assessed by comparing pre- and postoperative Rhinosinusitis Disability Index. Highly significant difference was noted when pre- and post-operative Rhinosinusitis Disability Index $(p=0.003)$ were compared. For patients with polyps, $\mathrm{P}$ value $=0.00$ and patients without polyps, $\mathrm{P}$ value $=0.00$.

\section{REFERENCES}

[1] Bro I. The role of bacteria in chronic rhinosinusitis. Otalarygol clin N Am 2005;38(6):1171-92.
[2] Wald ER. Microbiology of acute and chronic sinusitis in children and adults. Am J Med sci 1998; 316(1):13-20.

[3] Biel MA, Brown CA, Levinson RM, et al. Evaluation of the microbiology of chronic maxillary sinusitis. Ann Otolaryngolrhinol 1998;107(11 Pt 1):942-5.

[4] Bachert C, Gevaert P, Holtappels G, et al. Total and specific $\operatorname{IgE}$ in nasal polyps is related to local eosinophilic inflammation. J Allergy ClinImmunol 2001;107(4):607-14.

[5] Sieberling KA, Grammer L, Kern RC. Chronic rhinosinusitis and superantigens. Otolaryngolclin N Am 2005;38:1215-36.

[6] Bernsterin JM. Update on the molecular biology of nasal polyposis. Otolaryngol clin $\mathrm{N} A \mathrm{~m}$ 2005;38(6):1243-55.

[7] Liu CM, Hong CY, Shun CT, et al. Inducible cyclooxygenase and interleukin 6 gene expression in nasal polyp fibroblasts: possible implication in the pathogenesis of nasal polyposis. Arch Otolaryngol head neck surg 2002;128(8):945-51.

[8] Walker C, Williams H, Phelan J. Allergic rhinitis history as a predictor of other future disqualifying otorhinolaryngological defects. Aviat space Environ Aed 1998;69(10):952-6.

[9] Lane AP, Pine HS, Pillsbury HC. Allergy testing and immunotherapy in an academic otolaryngology practice a 20 years review. Otolarngol Head necksurg 2001;124(1):9-15.

[10] Suzuki M, Watanable T, Suko T, et al. Comparison of sinusitis with and without allergic rhinitis: characteristics of paranasal sinus effusion and mucosa. Am J Otolaryngol 1999;20(3):143-50.

[11] Lund VJ, Kennedy DW. Staging for rhinosinusitis. Otolaryngol Head Neck Sury 1997;117(3 Pt 2):S35-40.

[12] Report of the rhinosinusitis task force committee meeting. Alexandria, virginia, August 17, 1996. Otolaryngology and Head and Neck Surgery 1997;117(3 Pt 2):S1-68.

[13] Durr DG, Desrosiers MY, Dassa C. Impact of rhinosinusitis in health care delivery: the quebec experience. J otolaryngol 2001;30(2):93-7.

[14] Khalil HS, Nuzez DA. Functional endoscopic sinus surgery for chronic rhinosinusitis. Cochrane database syst Rev 2006;3:CD004458.

[15] Chan Y, Dales R, Lin M. The epidemiology of chronic rhinosinusitis in Canadians. Laryngoscope 2003;113(7):1199-205.

[16] Birch DS, Saleh HA, Wodehouse T, et al. Assessing the quality of life for patients with chronic rhinosinusitis using the rhinosinusitis disability index. Rhinology 2001;39(4):191-6.

[17] Deal RT, Kountakis SE. Signification of nasal polyps in chronic rhinosinusitis: symptoms and surgical outcome. Laryngoscope 2004;114(11):1895-905.

[18] Murthy DK, Murthy PSN, Verghese G, et al. Orbital complications of endoscopic sinus surgery. ANNALS of Ophthalmology and Glaucoma 1998;30:19-21. 